\title{
NOTES FROM PRACTICE
}

\section{UIT DIE PRAKTYK}

\section{A CONVERSATION BETWEEN THE ONE-WAY MIRROR AND THE COUCH: INSIGHT VERSUS REFRAMING}

\section{INTRODUCTION}

In this article I attempt to weigh up two diverse kinds of therapeutic -interventions against each other: insight and reframing. Insight seems to be the preferred intervention, especially in the field of psychiatry.

| Firstlyly, I will discuss insight from my point of reference. I will then discuss reframing as a therapeutic alternative. Lastly I will discuss a case study from my work. I will look at the therapeutetherapeutic implications in the light of the discussion.

I find myself in a unique position to undertake this task. I did my undergraduate studies with an emphasis on psycho-analysis. At first this was then obviously the theory I used in the therapy I conducted. I then completed my commenced-post-graduate studies with a purely ecosystemic emphasis. During this period I was also working in a chronic psychiatric hospital, where I could thus take an "objective look" at insight.

\section{INSIGHT:}

The development of insight in the client- seems to be one of the central objectives in treating mental illness or other psychological problems and difficulties. Although this is the means to an end in psyco analisyspsychoanalysis, other treatment modalities such as like Bbehavioural Ttherapy, RET therapy and Ecognitive Ttherapy embrace this therapeutic stance to some extentin some ways.

The idea of insight stems largely from Freud and the psychoanalytic perspective. But most psychological theories have drawn from this theory. If we look at psychoanalytic concepts, it is amazing to see how strong the influence of -psychoanalysis has been, even in "new" theories. I list below these concepts that I believe still plays a very active role in theories of helping today:

- Catharsis

- Subconscious

- Hypnosis

- Resistance

- Autonomy

- Insight

- Regression

- Transference and counter-transference

- Self-disclosure
- Interpretations

- Unconscious

- Free association

- Repression

- Defence mechanisms

- Manipulation

- Resistance

- Self-mastery

It thus comes as no surprise that many of these concepts and theirits application to helping areis very popular, even today.

Dilman (1988:1) summarises the psychoanalytic therapeutic aim as follows: "For the treatment 
analysis is supposed to flow from this understanding." He adds (1988:78): "With this exclusive interest in 'getting at the truth' or 'insight into oneself' on the part of the patient, psychoanalysis became equivalent to 'insight therapy'...."

The analyst makes use of free--association techniques in an attempt to expandenlarge the client's consciousness and self-understanding. This is brought about by the interpretations with which the therapist responds to the client. In this regard Freud saw himself in the capacity of the interpreter. He told the clients some truths about themselves as revealed by the free associations. This will lead them to insight into themselves (Dilman, 1988:81-83; Sanville, 1991:63). Insight therapy seems to imply that there is an objective truth out there that the therapist knows and has to get accressacross to the client.

Freud (in Dilman, 1988:116) claims that everyone is afraid of the truth, yet they have to confront certain truths about themselves that they are afraid of and deceive themselves into thinking that these truths are not it isn't there. The truth lies in our unconscious mind. Insight comes about when this truth is "discovered".

If the "cured state" is not forthcoming, the acquired insight would be labelled as "only superficial" or that the client is consciously or unconsciously resistant to therapeutic inputs ${ }_{2}-$ o - r not ready for psychotherapy as he/she is not "responding" as expected. Insight and its implications are never explored in theseis therapeutic processes. It might be possible that insight is not all it is supposed to be.

\section{THE CLIENT AND INSIGHT:}

The insight_-_driven helping process entails the client needing to accept the therapist's explanation ofaround the "illness or wrongness" in the client's mental functioning or life. Once he/she accepts this specific meaning or explanation, the beliefve seems to be that the "cure" is imminenteminent. This method seems to be applied mechanically regardless of what the patient brings to therapy. Watzlawick, Weakland \& Fisch (1974:104) wrotewrites that the therapist first attempts to teach the client a new language, then wants him to think in the new language, after which the therapist attempts to stimulate change by speaking in this language.

I want to argue that the identification of pathological meanings will lead to the identification of even more pathology, thus escalating in a recursive manner. This frame of reference is consistantconsistent with the systemic theories in that it is believed that meanings and even identity areis shaped through recursive interactiveonal processessprocesses. Dalos, Alisttair \& Strouthos (1997:371) addressed the same point of view when they stateds that: "This invariably involves the use (and abuse) of power to impose such meanings on people, and in turn apply sanctions,_such as exclusion or even enforced treatment." As a therapeutic relationship is an interaction that evokes meanings, it has a very definite influence on the system of beliefs that a client has.

De Shazer (1994:5) seems to agree when he finds that what we call "therapy" leads to a false beliefve in that we think we operate upon our clients. This misconception stems from the Greek root, which means "to cure" or "to nurse"-- Twhich makes one forget that therapy is in fact a conversation and an interactiveenal process.

An example might illustrate the point further. A patient presents with auditory hallucinations. $\mathrm{He}$ is diagnosed as suffering from schizophrenia and medication is prescribed. The therapist allocated to him starts therapy by explaining to him that he is a schizophrenic and the meaning and consequences of this. Schizophrenia is not merely a set of symptoms, but almost a total re- 
definition of the person. In a way it almost means that: "I'm no longer a person but a schizophrenic." What a painful communication to deal with! Yet the message remains clear: accept this "truth" or be regarded as a schizophrenic AND devoid of insight._An explanation of the problem does not equal a solution nor a change.

Dalos et_al. (1997:373) make the additional point that: “... once established, the extent to which people are capable of voluntarily altering their pathological labeles is questionable. Psychiatric labels are powerful in that they can impose a definition that leaves little prospect for change". They draw attention to the studies of Birchwood et al. (1987), Haley (1989) and Harding et al. (1987), which point out that psychosis is often a once-ee-off event. But the powerful view that psychosis is of an organic nature and is associatedreceived with consequences such as enforced medication, disempowerment and marginalisation will have the effect that the client might be forced to make a career of being a psychiatric patient.

Although the above example might be extreme, other processes of developing insight might be just as painful: dealing with unacknowledged feelings towards one's parents, redefinition of entire childhood memories, exposing characteristics of a client that are presented as the TRUTH and not negotiable. This establishing of the "truth" is called interpretation. Isn't it rather strange then that Freud himself (cited in Dilman, 1988:123) said: "Interpret! An ugly word. I don't like to hear it for it destroys all certainty. If everything is to depend on my interpretations, who is to say whether I interpret correctly?"

If the development of insight entails that a cure or change will naturally follow, why then do certain therapeutic relationships have to remain in place for years? And if certain problems in living are perceived and labelled as "mental tillness" and psychotropic medication is prescribed, how exactly will insight contribute to an improvement of a client's quality of life?

Again a question arises: will an-acceptance of a so-so-called illness and its consequences change anything? Or will it only keep in place exactly what we as therapists are trying to change?

\section{INSIGHT: NECESSARY OR DANGEROUS?}

I have encountered too many patients or clients whothat merely react to therapeutic interventions by saying: "You should know better_..._I can't do that! I'm a schizophrenic." Therapy can be such a profound process_..-_are we just making it impossible? What wouldill happen if we didn't present our clients with the medical model of truths? Or any other truths that we believe will contribute to insight?

Gergen (1985:268) has stateds in this regard: “... reality can never be known, and there are numerous ways to view the world. Problems are maintained when a person believes that only one view of the problem exists. White and Epston (1990:67) seems to supports this idea when they wrote in a more recent publication that once a client holds on to one set of beliefs, they close themselves off to other ways of resolving the problem."

Human behaviour, thought processes and mental states are....all such complex phenomena. We still don't know how each individual or group of individuals "really works". An "injection of insight" is thereforethus not necessarily therapeutic or useful. In fact, it sometimes provides the patient/client already stuck in a particular mind-set, behaviour or interaction the "permission" | to remain there-_- as long as they "understand why" their lives have come to this. Wetchler (1999:19) makes the point: "Therapist directives are simply one way of viewing the problem; 
placing therapist beliefs above client beliefs simply presents another dominant story that may prevsent more effective solutions from evolving."

It is my view that, because there is an inherent paradox in this communication ("Change is only possible when you develop insight into the fact that you can't change"), then frustration develops, especially in the therapist. Case notes on clinical files read something like this: "Patient has developed insight into his condition, but the labile moods and lack of motivation persist"s.

What should be the next move when they have developed insight? It is suggested that the very vehicle that should facilitate change (i.e. insight) has become exactly what keeps patients/ clients dependent and "sick".

\section{Reframing: "Lack of insight" redefined}

I'm tempted to suggest that the "lack of insight" be reframed as follows: "The patient has a strong set of beliefs and an ideology about himself that cannot be altered by outside inputs that he finds to be not useful to his situation. There are certain aspects of his reality that he wants to hold on to. Attempts to change this will have no therapeutic benefits as these beliefs provide the patient/client with the vantage point to believe in himself. Affirmation of this will provide mental energy to facilitate therapeutic change that he will benefit from most."

Therapists work so hard to create insight. Once they reach that goal, however, there is no clear way forward. They say: let me explain this to you and you have to accept it, regardless. Some form of enlightenment will follow when you do. But enlightenment seems etlusive ... understanding and acceptance are just not synonemoussynonymous with changing and growing.

\section{REFRAMING: A THERAPEUTIC ALTERNATIVE:}

It seems from the above that problems in living can be viewed as a "stuckness" in the way we think about our world. When we as therapists, therefore, encounter clients in therapy, we want to allieviate this "stuckness" by offering a climate where alternative ways of thinking can be examined.

Reframing can be a useful vehicle for therapeutic change. Reframing is a technique that Watzlawick et-al. (1974:95) defineds as follows: "To reframe, then, means to change the conceptual and/or emotional setting or viewpoint in relation to which a situation is experienced and to place it in another frame which fits the 'facts' of the same concrete sittuationsituation equally well or even better, and thereby changes its entire meaning." ReframingThe reframe attempts to change the meaning that is attributed to a situation. The philosoepher, Epictetus (1st century A.D.AD) said in this regard: "It is not the things themselves that trouble us, but the opinions that we have about these things" (in Watzlawick et_- al. 1974:95). We are said to create our own realities by the way we attach meaning to the world we live in as well as our experiences of it.

The goal of this essay is not, however, to teach the art of reframing. It is rather to provide therapists with the reassurance that there are alternative therapeutetherapeutic interventions to that of

insight. (The insight-reframe interventions will be placed in a practical framework when reframingit is discussed with case samples.) 
Papp and Imber-Black (1996:17) state in this regard: "When a therapist keeps defining the problem in a way that leads to more of the same, it is a signal to develop a new perspective." This entails changing not only the client's view, but also the way the therapist has been viewing the problem. If the perspective is not altered, the danger lies in the possibility that the client and therapist can become trapped in the problem. This will add to the client's already high levels of anxiety and sense of hopelessness.

What do we as therapists want to be for our clients? Teachers, demonstratersdemonstrators, philosophers or Mmasters in the art of living, having discovered the truth?_-Or can we become useful in the therapeutic process of change? Amundson (1996:475) came to the following conclusion: "...what is good is secondary to what is useful. That is, not all good and true ideas are automatically useful. In the domain of human behaviour, knowledge is less the discovery of facts than the ongoing accumuitlation of artifactsartefacts."

\section{CASE STUDY:}

I want to share one of my cases with the reader. I have changed the client's name to protect his | identity. He hads been a patient in a chronic psychiatric facility. He hads been through "insight therapy" and it didn't change his behaviour. I use reframes all the time in my work, so the case I present is not an exception. I chose to present this client because he seemed like "a lost case" at first, even to me. His symptoms seemed unchangeable and even the psychotropic medication didn't help him.

Patients come for therapy when they feel the need. It is not required offrom them. They schedule it as and when they feel the need.

A 34-year-old male, Cody presented himself for therapy. He had been diagnosed as a schizophrenic 10 years before. He hads been in hospital for the past-previous five 5 years. He complained of voices in his head. According to him, they told him what he should do and how he had tomust act. He indicated that he heards about five 5 different voices at any given time. They spokeeak in confusing ways all together, like crossed telephone lines, in his mind.

During the first session a lot of time was spent on the voices and the content of what they were saying. On the one hand, they were telling him to get married. He also wanted this for himself, but didn't see himself marrying any of the patients in the hospital. He also didn't have the opportunity to meet anyone outside the hospital. A reframe was presented as an intervention. The goal of the intervention was to give him control over the voices. It was combined with his wish for normality within a marital relationship. It is also interesting to note that the voices intensified when he thought about working towards discharge. The reframe was structured as follows: "The voices don't respect you. They want to keep you here. share you with someone else. They don't want you to get married. You need to persuade them to listen to you as you have been listening to them for the past $\underline{10}$ ten years."

The reframe attempts to change the meaning of the voices. It redefines themit as something that is within his control. He is not regarded in therapy as being ill. The voices are given some meaning that he can negotiate with. He accepted this reframe and was quite eager to start his negotiations.

During the second session (which took place about a week later), however, he indicated that the voices didn't want to listen to him. He was lying on the grass beforeprior to the session and was thinking about discharge when the voices intensified. This was regarded as a form of change as he had felt victimised by the voices before and now he was attempting to "take them 
on". He indicated that he could ean-hear them for about fives minutes and then they disappeared. They re-emerge $\underline{\text { d }}$ about hourly in this fashion.

Again this was reframed: "You must be doing something 'right' for the voices to disappear in this way. Otherwise, they would have been there all the time. You need to concentrate on what you do for them to disappear. You know the secret to do this unconsciously already. If you concentrate on the process, you will discover the tool to help you."

Again, the reframe attempteds to place the voices within Cody's control. The therapy didees not attempt to get to the "truth", but to give Cody another frame of meaning that couldean be useful to change the symptom.

By session 3 (which took place about three weeks later) the voices wereare becoming less of a problem. The conversation in therapy shifteds to his family and especially his problematic relationship with his father. A lot of painful aspects were discussed. Theseis includeds his feeling of having beenbeing rejected by his father, who sent Cody away to hospital. Cody wasis told to write a letter to his father during therapy. He couldean writesay anything in this letter. In the letter he toldtells his dad how he hads hurt him by sending him away. He hateds him for doing this to him. He also wroteites how his father hurts him every day even when he wasis far away. He leftaves the session in a tearful state.

During the fourth4th session (which took place the next day) he stateds that he wanteds to continue with the letter. He now wroteites that he forgaveives his dad and that he wanteds to come home. He wanteds a normal life. He wanteds to work and get married.

In the fifth5th session (about a month later) the voices wereare again overwhelming. This time, the following reframe wasis used: "Is it your father's voice that bothers you so much?" This wasis done because an interactional frame had been developed in the previous sessions. The voices wereare personified into a problematic relationship instaed instead of an illness. His relationship with his father had needs-to be healed and that was its-not some organic ailment that neededs medication. Cody respondeds by indicating that he heards his father's voice clearly. He saidys further that if he wasis discharged, he wanteds to get married. This wouldill be a way toof normaliseing his life. He could notan't do thatthis, however, as his father wiwould then be alone. (His mother hads passed away.) How wouldill his father cope if Cody gotets a wife before his father?

The reader's attention is drawn to the change that has taken place in this process. Firstly, the voices were redefined as in Cody's control instead of being an illness. They became less important in the subssequent sessions and re-emerged when painful interactional problems were discussed. The voices themselves changed from being an unknown bunch of speakers to the voice of his father.

In responsse to this Cody was given the intervention "just to think about his future and what he wanteds for it." He was urged not to do anything about its as it could may-well be too soon for all that. This was done in an attempt to underline the previous interventions of control. As a psychiatric patient, control over one's life is not a given. Developing reflection on this aspect can change some of the meanings around feelings of hopelessness. Thinking about something strengthens one's notion of doing it. It creates the urge to put the dreams into practice.

Now discharge was in progress for Cody. By the sixth session (which took place about two months later) his voices were under control. He indicated that they were it was-no longer a probblemproblem. He voiced a fear of theirm returning when he would beis at home with his father As a resnonse 0 this a reframe was again formulated. "Imagine that evervone hears 
voices at some point. Even the people in your family. Maybe you're just the only one that admits it. Maybe you can look and see if you can catch a glimpse ofat what they look like when they hear themit." This seemed useful in order to assure Cody that he wasis not the only one with "symptoms". Psychiatric patients often feel alone and stigmatised. This kind of reframe empowers them to feel more at ease with themselves. They also find it hard to be with people who are that is not regarded as "mentally ill", because they get used to being with people who arethat is. "Spreading the symptom" might be a useful way to counteract this.

CodieCody went home. He has been in the community for the past three years now.; A readmission due to relapse has not been necessary.

\section{THERAPEUTIC IMPLICATIONS:}

Firstlyly, I want to quote De Shazer (1994:33)ites: "To have a therapeutic enterprise there needs to be both client and therapist" (italics added). We really need to see and hear clients. They make change possible with what they bring for us to feel. They don't necessarily understand or accept what we say if this is not done in their language or frame of reference. We need to discover alternatives and solutions with them.

| Secondly, -I want to emphasise that the theory of reframing can "fit" with-anyone, as it is constructed in the language and based on the principles that the client brings to us. It is not concerned with getting to the truth (whatever that might be), but in creatively constructing frames that will allow the client to move to different, less painful patterns of interaction.

Thirdly, there are alternatives to therapeutic practice from whichthat clients can benefitfrom. Watzlawick et:-al. (1974: 31-39) calleds this the "more of the same" principle. When we as therapists realizerealise that our interventions aren't producing what we - or more importantly, our clients - are looking for, we need to look at what we are doing. Our solutions or interventions might be what can be called the "problem". Watzlawick et_al. (1974:36) addeds: "...that under certain circumstances problems will arise purely as a result of wrong attempts at changing an existing difficulty:".

\section{CONCLUSION:}

A quotation from Amundson (1996:484) provides a neat summing up of the point of departure for this article: "I shall find neither comfort nor final response in any belief concerning specified ways for all of us to live; I am interested in journeys not destinations. I shall

| especially not separate myself from you by any suggestion that I know the dance steps or the possess the code book for all of us. There is no overarching reason or way to be, only a realizationrealisation that certain being or reasoning practices may be more convenient than others. While we search for greater "vehicles of convenience" (that is theories and practices), we also accept that perhaps the best we can hope for is noncoerced consensus arising from lively and useful conversation:".

\section{REFERENCES}

AMUNDSON, J. 1996. Why pragmatics is probably enough for now. Family Process, 35:473486.

BIRCHWOOD, M.; MCGORY, P. \& JACKSON, H. 1987. Early intervention in schizophrenia. British Journal of Psychiatry, 170:2-5. 
DALOS, R.; ALISTłAIR, N. \& STROUTHOS, M. 1997. Pathways to problems- the evolution of "pathology". The Association of Family Therapy Practice and Systemic Practice, 19:369-399.

DE SHAZER, S. 1994. Words were originally magic. New York: Norton.

DILMAN, I. 1988. Freud, insight and change. New York: Basil Blackwell, Inc.

GERGEN, K. 1985. The social constructionist movement in modern psychology. American Psychologist, 40:266-275.

HALEY, J. 1989. The effect of long-term outcome studies on the therapy of schizophrenics. Journal of Marital and Family Therapies, 2:127-132.

HARDING, C.M.; ZUBIN, J. \& STRAUSS, J.W. 1987. Chronicity in schizophrenia, fact, partial fact or artifactartefact? Hospital and Community Psychiatry, 38:477-486.

PAPP, P. \& IMBER-BLACK, E. 1996. Family themes: TranmissionTransmission and transformation. Family Procesprocess, 35:5-20.

SANVILLE, J. 1991. The playground of psychoanalytic therapy. London: The Analytic Press.

SZASZ, T. 1970. Ideology and insanity. New York: Anchor.

WATZLAWICK, P; WEAKLAND, J.H. \& FISCH, R. 1974. Change: Principles of problem formulation and problem resolution. New York: Norton.

WETCHLER, J.L. 1999. Narraitive treatment of a woman with panic dosorderdisorder. Journal of Faamily Psychotherapy, 10(2):17-30.

WHITE, M. \& EPSTON, D. 1990. Narrative means to therapeutic ends. New York: Norton. 